\title{
Montes Veciñais en Man Común e Baldios: Unha análise comparativa das propiedades comunitarias de Galicia e Portugal
}

\author{
Montes Veciñais en Man Común and Baldios: A comparative analysis between common \\ properties of Galicia and Portugal
}

DAMIÁN COPENA RODRÍGUEZ

GIEEAH-Universidade de Vigo

https://orcid.org/0000-0003-1329-3116

decopena@uvigo.es

\begin{abstract}
RESUMO
A existencia de propiedade comunitaria é posiblemente a característica máis singular do réxime de propiedade dos montes de Galicia e de Portugal. As Comunidades de Montes Veciñais en Man Común e os Baldios xestionan amplas áreas de monte compartindo características e similitudes, tanto no relativo á súa evolución histórica como no que se refire ás problemáticas sociais, económicas e ambientais que padecen.

O presente traballo realiza, a partir de diferentes metodoloxías entre as que destacan as vinculadas coa investigación participativa, unha comparativa entre estas dúas figuras de xestión colectiva do monte, caracterizándoas, debullando o marco normativo baixo o que se regulan e realizando unha aproximación inicial ao contexto produtivo no que se atopan, ás actuais ameazas coas que contan e ás oportunidades existentes a partir de novas lóxicas vinculadas coa sustentabilidade. O traballo mostra como están comezando a aparecer novos ámbitos de manexo vinculados coa multifuncionalidade nos dous espazos xeográficos.
\end{abstract}

Palabras clave: Sustentabilidade, Acción colectiva, Comúns, Gobernanza.

\section{Abstract}

The existence of community property is possibly the most unique feature of the property regime of Galician and Portuguese forest: the Comunidades de Montes Veciñais en Man Común and the Baldios. Both manage vast areas of forests and share characteristics and similarities, in relation to their historical evolution and also in regard to the social, economic and environmental problems they suffer.

The present work is based on different methodologies, underlining the participatory research, and carries out a comparison between these two institutions of collective management of the forest. In 
this research we characterize them, analyse the regulatory framework and do an initial approach to the productive context in which they are. Finally, the paper goes into detail about the current threats and the new opportunities for sustainability management. The paper shows how new management areas linked to multifunctionality are beginning to emerge in both geographic spaces

Keywords: Sustainability, Collective action, Common, Governance.

\section{INTRODUCIÓN}

A xestión dos recursos naturais por parte das comunidades locais forma parte do debate científico das últimas décadas (Araral, 2014). Certamente, nun contexto socioeconómico e ambiental onde o mantemento do modelo predominante se vincula cunha elevada taxa de apropiación dos recursos, esta discusión resulta de interese co obxectivo de procurar o avance cara modelos máis sustentables do manexo dos recursos naturais que permitan a mellora da calidade de vida das poboacións locais sen dilapidar os recursos endóxenos (Agrawal, 2014).

Dentro deste debate, a existencia dos denominados recursos de uso común (RUC), nos que é difícil excluír ou limitar o seu acceso aos usuarios (Ostrom, 1990), ten propiciado a aparición de diferentes análises sobre cal é a maneira máis eficiente de xestionar esta clase de recursos. Deste xeito, hai autores que indican a necesidade da privatización ou estatalización dos mesmos para garantir que non se esquilmen dentro da lóxica dos resultados agardados baixo as premisas da traxedia dos comúns (Hardin, 1968). Non obstante, nas últimas décadas teñen gañado relevancia outras propostas que sinalan que o manexo dos RUC baixo as institucións de acción colectiva pode ser eficiente e mesmo máis desexable que as outras modalidades propostas (Ostrom, 1990). Nesta discusión, se encadran tamén as institucións que xestionan os recursos de propiedade comunitaria, que son tamén parte da ampla e complexa temática dos comúns (Bassi e Carestiato, 2016). Seguindo a Ostrom (1994), os montes de propiedade comunitaria ${ }^{1}$ se encadrarían dentro desta clasificación como RUC, polo que a análise e o debate sobre o seu manexo por parte das comunidades locais resulta de interese na discusión académica actual.

Dentro do debate sobre o manexo dos RUC existe un importante desacordo entre cales son os modelos máis adecuados para garantir unha xestión sustentable destes recursos naturais (Gautam e Shivakoti, 2005). Así, a privatización ou a estatalización se presentan habitualmente como solución ás premisas establecidas na traxedia dos comúns que indican que os RUC serán sobreexplotados polo incentivo racional de cada un dos usuarios a

1 Entre os que se encontran tamén o noso "monte" que ten un concepto amplo e complexo, vinculándose con diferentes superficies, tal e como sinala a propia definición da Lei de Montes de Galicia: "enténdese por monte ou terreo forestal todo terreo en que vexetan especies forestais arbóreas, arbustivas, de matogueira ou herbáceas, sexa espontaneamente ou que procedan de sementeira ou plantación, que cumpran ou poidan cumprir funcións ambientais, protectoras, produtoras, culturais, paisaxísticas, sociais ou recreativas". 
maximizar a súa utilidade individual (Hardin, 1968). Neste senso, na xestión dos recursos naturais, os dereitos de propiedade son un aspecto clave que determina cales son as posibilidades de xestión por parte das comunidades locais, sendo xeralmente recoñecidos catro tipos de propiedade: privada, común (compartida, colectiva ou comunal), pública (Estado) e de acceso aberto (Slaev e Collier, 2018). Os dereitos de propiedade comunitarios ou colectivos, que deben ser recoñecidos, aplicados e garantidos polas comunidades e os estados (Moroni, 2018), se encontran a medio camiño entre o privado e o público.

Os recursos que son de propiedade colectiva insírense, por tanto, dentro desta lóxica dos RUC e, certamente, contan con moita importancia nalgunhas áreas do planeta. Así, estímase que hai 8,5 billóns de hectáreas que son propiedade de comunidades rurais. Delas, en torno a unhas 513 millóns de hectáreas están vinculadas con bosques que teñen sido oficialmente recoñecidos como propiedade de pobos indíxenas e comunidades locais (Graziano et al., 2015). Unhas áreas de propiedade colectiva, como as que son xestionadas por institucións como as CMVMC galegas ou os Baldios portugueses, que poden ter un papel relevante no desenvolvemento rural (Bassi e Carestiato, 2016).

As propiedades comunitarias que podemos encontrar no noroeste peninsular, tanto as existentes en Galicia (Estado español) como as localizadas en áreas do centro e do norte de Portugal, encádranse neste contexto científico. Certamente, as Comunidades de Montes Veciñais en Man Común (CMVMC) e os Baldios, que xestionan importantes áreas xeográficas de monte, son entidades comunitarias con relevancia cuantitativa e cualitativa no manexo territorial e que, como imos analizar no presente traballo, contan con similitudes e diferenzas normativas e de contexto. Nos últimos anos estas propiedades colectivas do noroeste peninsular están acadando maior interese na literatura científica Así, nos Montes Veciñais se ten analizado a súa gobernanza desde unha perspectiva institucional (Caballero, 2014), o cumprimento dos principios de acción colectiva postulados por Ostrom (Alló e Loureiro, 2016) ou o nivel e a causa dos conflitos asociados coa propiedade comunitaria do monte galego (Gómez-Vázquez et al., 2009). Pola súa banda, nos Baldios tamén existen recentes traballos na literatura como o que avalía as dinámicas históricas (Lopes et al., 2013), os novos ámbitos de aproveitamento e de dinamización local (Serra et al., 2017). O presente traballo pretende aportar novos argumentos nesta discusión a partir da análise comparativa, feita desde diferentes ángulos, entre as dúas institucións de acción colectiva, amosando a existencia de novos modelos incipientes de manexo das áreas comunitarias vinculados coa multifuncionalidade.

Para poder desenvolver o presente traballo de investigación foi preciso a utilización de diferentes metodoloxías, entre as que destacan as vinculadas coa investigación participativa. Así, foi realizada unha análise da literatura científica vinculada co obxecto de estudo e recompiláronse os dados estatísticos existentes nas fontes de información públicas. Por outra banda, se teñen estudado os documentos normativos que exercen de marco regulador das propiedades comunitarias. Finalmente, para poder obter información cualitativa, resultou necesario a utilización de ferramentas vinculadas coa investigación participativa (Cassell e Symon, 2004; Simón et al., 1999; Santos Castroviejo, 2003) a par- 
tir da realización de traballo de campo e de entrevistas semiestructuradas con CMVMC e Baldios clave, ademais de facer un seguimento dos debates existentes nas entidades asociativas específicas que as agrupan, coa participación nos principais eventos recentes das propiedades comunitarias en Portugal $^{2}$ e $\mathrm{Galicia}^{3}$, o que permitiu ter un coñecemento directo dos debates actuais existentes dentro dos ámbitos asociativos das entidades comunitarias.

\section{A PROPIEDADE COMUNITARIA EN GALICIA E PORTUGAL}

\subsection{Dinámicas históricas da propiedade comunitaria aos dous lados do Miño}

Os territorios de Galicia e o norte e o centro de Portugal son áreas onde predomina o carácter forestal, considerando como tales as áreas arborizadas e os terreos ocupados pola matogueira. Estes espazos foron a base do sistema agrario tradicional durante séculos (Bouhier, 2001) a partir das funcións que subministraban: a obtención de biomasa para producir abono a partir do estrume, elemento fundamental para o mantemento do sistema de fertilización mediante a utilización do complexo monte/cultivo/prado; a biomasa como alimento para o gando, maior e menor, mediante o pastoreo no monte; a obtención de carne e de leite para a alimentación das unidades económicas campesiñas; a utilización do monte como lugar de cultivo para a produción de cereais como o centeo e, en menor medida, o trigo a partir das estivadas; fornecer tecidos e fibras como a lá, materiais para construción, etc; (Baptista, 2010; Balboa, 1990).

Non obstante, as áreas de monte foron perdendo paulatinamente desde finais do século XIX, ás dúas beiras do Miño, as súas funcións tradicionais. Este feito, que se produce de maneira máis acusada a partir dos anos 40 do pasado século $\mathrm{XX}$, ten sido estudado por diferentes autores (Estevão, 1983; Boquete, 2000; Soto e Fernández, 2000) que nos indican como o proceso de ocupación de áreas con manexos en moitos casos colectivos e os proceso de forestación masiva non foron aceptados polas poboacións locais que perdían a posibilidade de usar un elemento básico para as súas economías de subsistencia. Neste senso, resulta interesante constatar como unha análise dos procesos históricos e dos conflitos vinculados coas áreas de propiedade comunitaria amosa que as dinámicas das propiedades comunitarias nos séculos XX e no principio do século XXI teñen moitos puntos en común nos dous territorios. Este feito ven propiciado pola case coincidencia temporal nos períodos ditatoriais de Franco e Salazar que impulsaron o

2 Concretamente a VI Conferência Nacional dos Baldios, organizada pola BALADI-Federação Nacional dos Baldios-, que tivo lugar en 2017 en Vila Real (Portugal) e o III Congresso Europeu das Áreas Comunitárias de 2018 en Miranda do Corvo (Portugal).

3 Referímonos ao VI Congreso Galego de Comunidades de Montes, organizado pola Organización Galega de Comunidades de Montes Veciñais en Man Común, e que foi realizado no 2018. 
fomento do produtivismo no monte con especies de crecemento rápido, provocando a perda de moitos aproveitamentos tradicionais mediante a ocupación de pasteiros e áreas utilizadas para o gando. Como consecuencia, as áreas de monte xestionadas polo Estado destináronse a desenvolver aproveitamentos produtivos ligados a intereses empresariais vinculados fundamentalmente coa pasta de papel. Por outra banda, a recuperación das áreas comunitarias ten lugar nun contexto onde a poboación local perdera a conexión co monte e a necesidade da súa utilización como elemento base para manter as economías labregas familiares de subsistencia (Brouwer, 1995). Os terreos recuperados para o manexo e utilización veciñal xa non eran os mesmos que décadas atrás, principalmente pola xeneralizada e agresiva ocupación forestal co conseguinte custe de oportunidade destas áreas. Neste contexto de rápidas mudanzas socioeconómicas a integración directa destes espazos no mantemento das economías agrarias locais estaba tamén case desaparecida en moitos dos lugares de Galicia e de Portugal.

\subsection{Caracterización e contexto normativo das CMVMC e dos Baldios}

Partindo do feito de que no territorio galego e no centro e norte de Portugal existen institucións de xestión do territorio vinculadas coa acción colectiva e coa propiedade comunitaria das áreas de monte, cómpre coñecer a súa relevancia a nivel cuantitativo e facer unha aproximación a aspectos cualitativos destas entidades de ámbito colectivo. En primeiro lugar, antes de entrar especificamente na análise nas propiedades comunitarias, cómpre sinalar a relevancia que ten a superficie forestal nos dous territorios, xa que representa en torno ao 35,4\% da superficie de Portugal (ICNF, 2013) e máis do 60\% da superficie galega (IGE, 2016), porcentaxe esta última somentes equivalente a algúns países do norte de Europa. En segundo lugar, é necesario ter en conta que tanto Galicia como Portugal comparten un réxime de propiedade do monte moi diferente ao existente noutros lugares de Europa. Así, contan con características comúns e singulares como a escasa importancia que ten a propiedade pública nas áreas forestais. Os montes públicos, que son os pertencentes ao Estado, ás comunidades autónomas, ás entidades locais e a outras entidades de dereito público ${ }^{4}$, apenas representan o $2 \%$ do monte galego e o $3 \%$ do monte de Portugal, as porcentaxes máis baixas a nivel europeo (Serra et al., 2017).

En terceiro lugar, tal e como se ten sinalado con anterioridade, os dous territorios comparten a importancia territorial da superficie comunitaria, aínda que con diferente contexto normativo. No caso portugués a Constituição da República de 1972 recoñeceu a existencia de tres clases de propiedade en Portugal: a pública, a privada e a ligada ao sector cooperativo e social, incluíndo dentro de este último "os medios de produción comunitarios, posuídos e xestionados polas comunidades locais" ${ }^{5}$. Pola contra, no caso

4 Artigo $11^{\circ}$ da Lei 43/2003, do 21 de novembro, de montes.

5 Tal e como se sinala no artigo 82 "Sectores de propriedade dos meios de produção" da Constituição da República Portuguesa. 
galego, ao non existir esta caracterización da propiedade comunitaria dentro da Constitución española, os montes veciñais son un ámbito singular que se encadra dentro da propiedade privada. Deste xeito, os montes veciñais están caracterizados na lexislación como privados-colectivos.

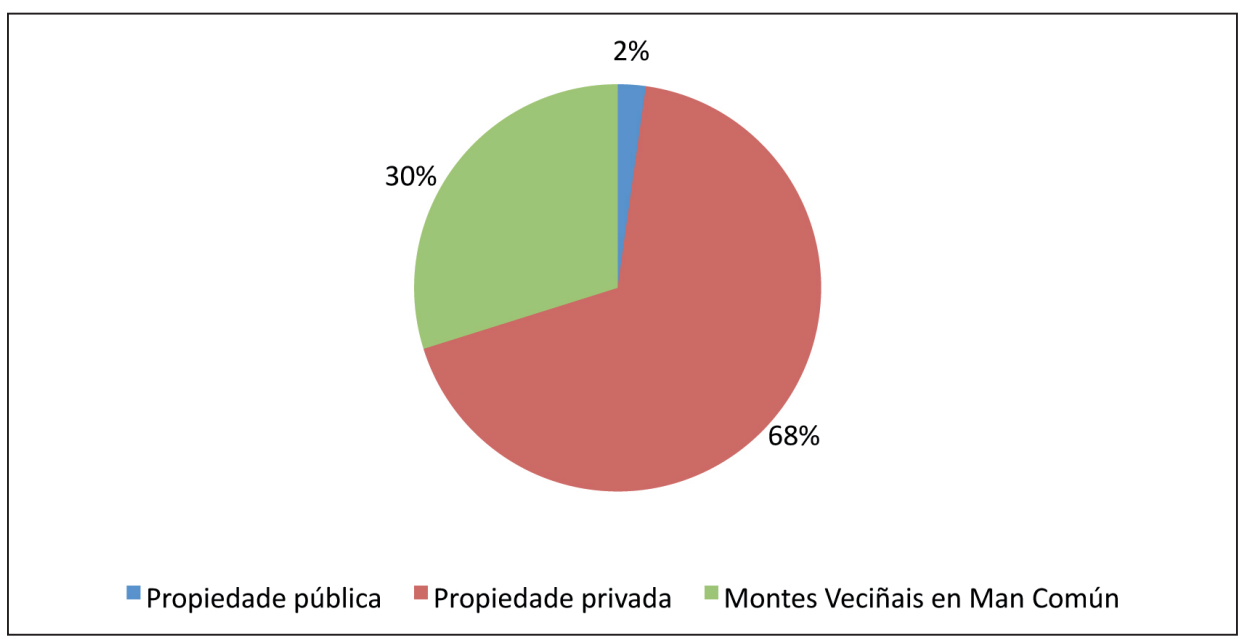

Figura 1. Caracterización da tipoloxía de propiedade do Monte en Galicia. Porcentaxe. 2011. Fonte: Elaboración propia a partir do Ministerio de Agricultura, Alimentación e Medio Ambiente (2008).

Neste senso, tanto as leis de montes do Estado como a de Galicia recollen a definición dos Montes Veciñais en Man Común que son considerados montes privados, de natureza xermánica, que pertencen colectivamente, e sen atribución de cotas, ás respectivas comunidades veciñais titulares. Están suxeitos, ás limitacións de indivisibilidade (as propiedades veciñais non se poden repartir entre a veciñanza); inalienabilidade (os montes veciñais non se poden mercar nin vender); imprescritibilidade (esta clase de propiedades non perden as súas características ao longo do tempo) e inembargabilidade (non resulta posible embargar os Montes Veciñais en Man Común). Estas son características que chocan de fronte coa lóxica do mercado e do propio sistema capitalista, polo que podemos considerar que son "anomalías" dentro do contexto económico predominante. Certamente, as condicionantes inherentes ás propiedades comunitarias xunto co seu carácter democrático confírenlles potencialidades para o desenvolvemento de iniciativas con racionalidades non curtopracistas nin economicistas convencionais, ligadas á lóxica do ben común e a racionalidades de ámbito colectivo, onde prime a compoñente da sustentabilidade.

Pola súa banda, en Portugal os Baldios son actualmente definidos pola normativa en vigor, Lei n. ${ }^{\circ}$ 75/2017 de 17 de agosto, como os terreos con as súas partes e equipamentos integrantes, posuídos e xestionados por comunidades locais, aínda que ocasionalmen- 
te non estean a ser obxecto de aproveitamento pelos compartes, ou carezan de órganos de xestión regularmente constituídos ${ }^{6}$. Esta figura, tal e como sinalan diferentes autores, conta cunha importante relevancia territorial actual para a xestión colectiva do territorio, aínda que tamén se constata a súa paulatina perda de importancia relativa ${ }^{7}$. Así, no traballo de Baptista et al. (2002) sinálase unha área de máis de 378.000 ha para un total de 671 Baldios $^{8}$. Por outra parte, Serra e Ferreira (2017) indican que a propiedade comunitaria en Portugal abarca en torno ás 500.000 hectáreas vinculadas a unhas 1.440 unidades de Baldios. No mesmo senso, os dados da Comissão Nacional para a Valorização dos Territórios Comunitários amosan como perto do $14 \%$ da superficie forestal de Portugal é de carácter comunitario, dado case coincidente co sinalado por Serra et al. (2016).

Un problema relevante para os Baldios consiste na inexistencia dun catastro nas áreas forestais con presenza das propiedades comunitarias o que dificulta poder ter un coñecemento máis exacto da superficie vinculada coas institucións que xestionan a propiedade colectiva. No mesmo senso, a falta de certezas no tocante aos límites territoriais favorece tamén a aparición de diferentes problemáticas, como as vinculadas coas ocupacións e perdas de terreo da veciñanza ante entidades públicas como as Juntas de Freguesía ou as apropiacións de terreos por parte de propietarios privados. Mais, o que resulta evidente é que a día de hoxe esta figura aínda conserva grande relevancia nas áreas serranas. O groso da superficie dos Baldios portugueses está nas áreas do norte limítrofes do territorio galego destacando o caso dos distritos de Vila Real e de Viana do Castelo (ver figura 2), aínda que tamén existen importantes extensións comunitarias en distritos do Centro de Portugal continental, como por exemplo na Serra da Lousã.

Pola súa banda, no caso de Galicia, existen máis dados relativos á situación da propiedade comunitaria. Segundo a explotación do rexistro dos Montes Veciñais en Man Común no ano 2012 hai no territorio galego 3.215 montes clasificados, cunha superficie asociada de case 667.000 has. A distribución provincial é moi desigual, destacando claramente o caso de Ourense que conta cunha grande parte da superficie comunitaria con unhas 277.000 has (o 41,5\% da total que hai en Galicia. Despois está Lugo con 207.000 has e Pontevedra con 134.000 has. A Coruña é claramente a provincia con menor representación desta propiedade con apenas 47.600 has. No territorio do minifundio o tamaño medio dos MVMC é de en torno ás 230 Ha (Marey-Pérez et al., 2010), o que lles confire potencialidades produtivas de interese e permite o desenvolvemento de aproveitamentos extensivos nas súas superficies veciñais.

6 A actual Lei dos Baldios establece una serie de casuísticas específicas baixo as que se encadra a definición de baldio, vinculada co denominado "regime florestal" e mesmo coa adquisición de terreos polas comunidades locais.

7 Aínda que resulta tamén é preciso salientar a falta de dados públicos fiables sobre a importancia cuantitativa e as dinámicas territoriais que teñen experimentado os Baldios.

8 A finais dos anos trinta do século XX en Portugal había máis de 507.000 hectáreas de Baldios cun grande nivel de atomización ao existir unhas 7.638 unidades de propiedade comunitaria (Lopes et al., 2013). 


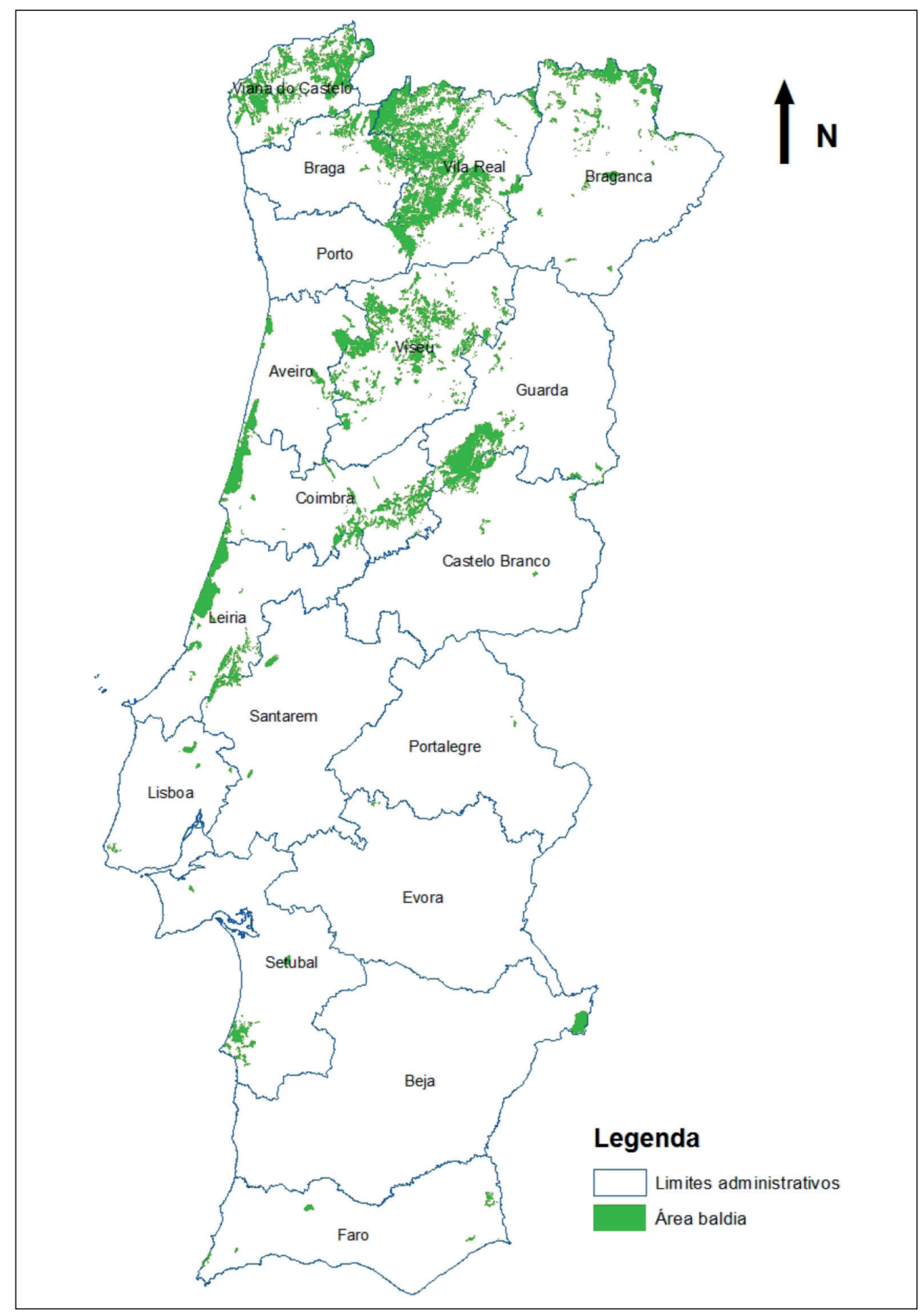

Figura 2. Distribución dos Baldios en Portugal continental.

Fonte: Federação Nacional dos Baldios-BALADI. 
A distribución territorial das áreas comunitarias en Galicia fica recollido para o ano 2012 na figura 3. Como se pode observar, a práctica totalidade das Comarcas galegas conta con montes veciñais en man común, aínda que o groso da superficie está situado ao sur de Galicia. Se facemos esta análise a nivel de concello podemos constatar como hai Monte Veciñal en 254 do total dos concellos galegos. Mesmo hai municipios, localizados no sur de Galicia en áreas limítrofes con Portugal, con máis do $70 \%$ de superficie veciñal.
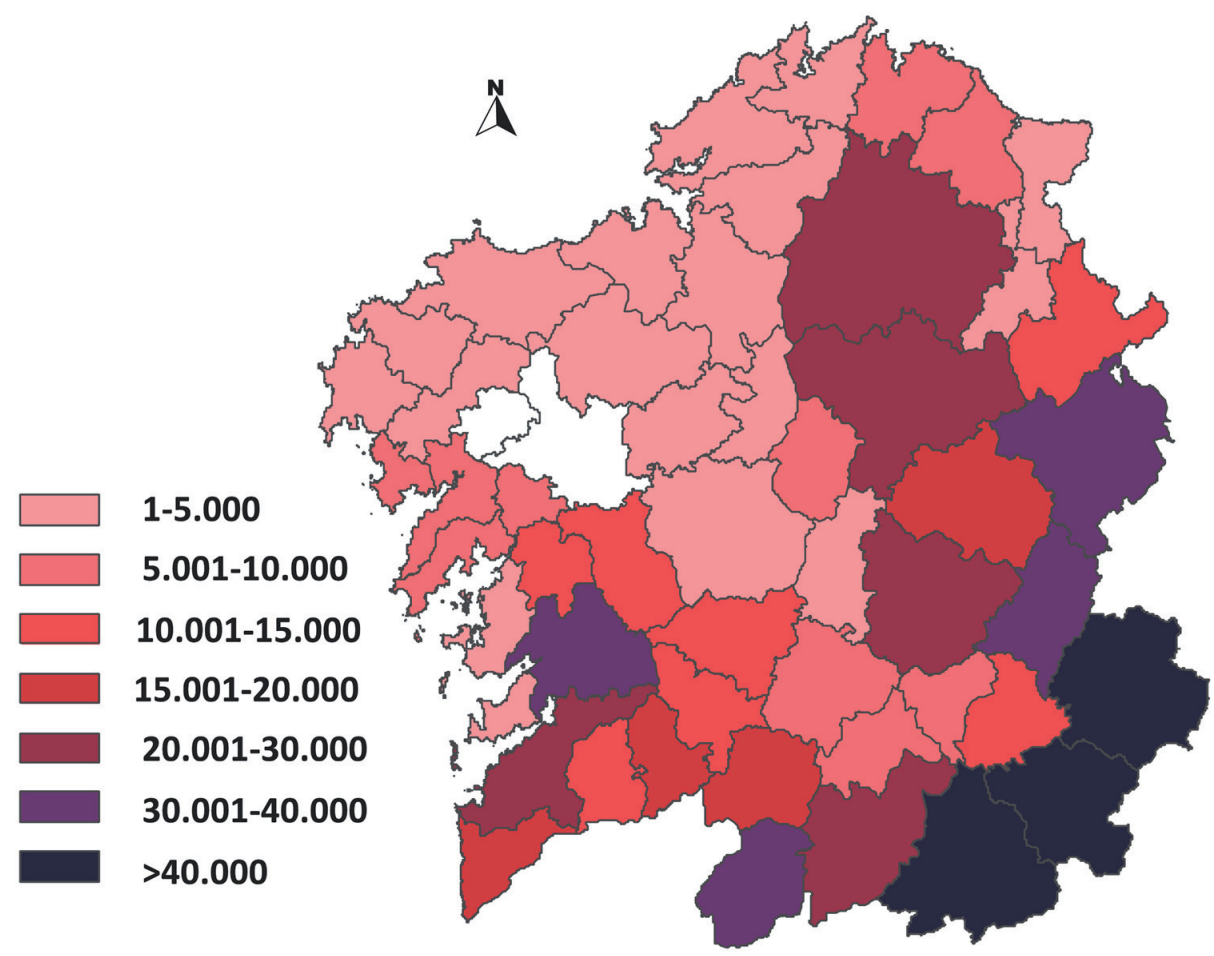

Figura 3. Caracterización da superficie veciñal por Comarcas en Galicia. 2012. Hectáreas. Fonte: Elaboración propia a partir da Explotación do Rexistro de Montes Veciñais de Man Común da Consellería do Medio Rural.

Como temos indicado anteriormente, as CMVMC e os Baldios teñen características que as fan singulares. Unha delas é o feito de que a participación está ligada directamente á residencia no lugar ou parroquia propietaria do monte, aínda que con diferenzas para cada unha das figuras comunitarias. É dicir, teñen un carácter inclusivo, non son entidades pechadas, senón que as persoas que forman parte da Comunidade van variando no tempo. Deste xeito, cada individuo que se traslada a vivir a un lugar ou parroquia que conte con Monte Veciñal en Man Común ou Baldio pode formar parte da figura de xestión colectiva participando na toma de decisións e nos aproveitamentos agroforestais 
do Monte. Aínda así, unha das diferenzas fundamentais que se constatan entre CMVMC e Baldios ven derivada da delimitación específica da persoa participante. Así as persoas comuneiras ou compartes teñen condicións diferentes na lexislación reguladora. No caso portugués os compartes, que son os titulares dos Baldios, caracterízanse como os cidadáns con residencia na área onde se sitúan os correspondentes inmobles, no respecto polos usos e costumes recoñecidos polas comunidades locais, podendo tamén ser atribuída pola Assembleia de Compartes esa consideración a cidadáns non residentes. Polo tanto, o criterio fundamental para ser comparte consiste na residencia no lugar con Baldio9. No caso galego, a definición de comuneiro/a é diferente. Así, terán a condición de veciños comuneiros aquelas persoas titulares de unidades económicas, produtivas ou de consumo, con casa aberta e residencia habitual independente dentro da área xeográfica sobre a que se asente o grupo social ao que tradicionalmente estivese adscrito o aproveitamento do monte, podendo establecerse estatutariamente un prazo mínimo de residencia para adquirir a condición de comuneiro, que, en ningún caso, poderá ser superior a un ano ${ }^{10}$. A definición que establece a normativa portuguesa é, por tanto, máis ampla e flexible que a galega, favorecendo o incremento do número de membros da comunidade, a participación das mulleres e, potencialmente, o recambio xeracional, un dos principais problemas existentes en Galicia. Non obstante, esta caracterización tamén resulta criticable ao posibilitar un número de compartes dificilmente xestionable nun hipotético contexto de grande participación social, (que certamente non é a norma actualmente. Pola contra, no caso galego a vinculación estatutaria soe indicar, en concordancia coa normativa autonómica, a condición de un veciño comuneiro un veciño por cada unidade familiar, o que favorece que a media de idade das asembleas sexa elevada e dificulta claramente o recambio xeracional e unha maior participación das mulleres nos órganos xestores e de decisión. Precisamente, esta cuestión foi tratada no último congreso das Comunidades de Montes Veciñais sinalando a necesidade de facer un esforzo colectivo para favorecer un cambio neste senso.

O proceso decisorio das dúas institucións comunitarias é democrático. Así, a veciñanza comuneira e as persoas compartes teñen capacidade de participación e decisión nas institucións de manexo do monte, xa que tanto as CMVMC como os Baldios organízanse en asemblea. Esta ten que ser convocada anualmente en convocatoria ordinaria un mínimo de dúas veces en Portugal e unha en Galicia. Da asemblea de compartes e de comuneiros saen os órganos xestores das entidades colectivas: a Xunta Reitora ${ }^{11}$ nas CMVMC e o Conselho Directivo ${ }^{12}$ nos baldios. Estes Órganos son os que se encargan das tarefas

9 Esta caracterización, que xa ven do cambio normativo que tivo lugar no ano 2014, rompe coa anterior definición do ano 1993 na que os compartes se vinculaban cos moradores de unha ou varias freguesías ou parte delas, que segundo os usos e costumes, tiñan dereito ao uso e utilización do Baldio.

10 Tal e como aparece definido na Lei 2/2006, do 14 de xuño, de dereito civil de Galicia.

11 A Xunta Reitora é o órgano de goberno, xestión e representación das comunidades, sendo elixida por maioría simple en votación da asemblea xeral, por un prazo máximo de catro anos.

12 Que, entre outras atribucións, ten que dar cumprimento e execución ás deliberacións da Asemblea de compartes e propor os planos de utilización dos recursos da propiedade comunitaria. 
básicas de manexo diario das propiedades comunitarias. Finalmente, dentro do contexto de xestión e control cómpre sinalar que no caso portugués existe un órgano adicional vinculado cos Baldios, a Comissão de fiscalização, con competencias na contabilidade, no relativo á fiscalización do cumprimento dos planos de utilización e coa función de verificar o respecto ás regras de protección do monte e do ambiente.

\section{CONTEXTO PRODUTIVO, AMEAZAS E RETOS DAS PROPIEDADES COMUNITARIAS}

As propiedades comunitarias de Galicia e Portugal comparten na actualidade un contexto produtivo de forestación masiva vinculada cos procesos de plantacións ligados ás dictaduras e tamén coas políticas públicas das últimas décadas que incentivaron as especies de crecemento rápido. Os dados públicos indican que as plantacións de eucalipto para pasta de papel (principalmente Eucaliptus globulus) teñen gañado importancia relativa nas últimas décadas. Así, en Portugal o eucalipto é a principal ocupación forestal con 812.000 ha e o Pinus pinaster unhas 714.000 ha (ICNF, 2013). Pola súa banda en Galicia, das máis de 2 millóns de hectáreas de uso forestal, máis do $70 \%$ está arborado. Desta superficie, un $39 \%$ correspóndese con coníferas e o $26 \%$ con eucaliptais (Consellería do Medio Rural, 2018). Este feito propicia que a orientación produtiva dos montes derive fundamentalmente cara usos madeireiros. O dato de Galicia, cunhas cortas de madeira que representan o 52\% do total do Estado, dan conta do nivel de intensificación existente (Ministerio de Agricultura, Pesca y Alimentación, 2016). O custe de oportunidade dos terreos ocupados con especies de crecemento rápido resulta evidente, xa que esta clase de aproveitamentos entra en conflito con outros máis tradicionais e ligados á inserción do monte no complexo agrario, nomeadamente co aproveitamento gandeiro en extensivo. Aínda así, cómpre salientar que no conxunto dos MVMC está situación non é tan extrema. Segundo os dados do IFN o 51,5\% da superficie veciñal está arborizada, aínda que unha análise provincial amosa como é o caso de Ourense con 158.000 ha veciñais de mato a que rompe a lóxica forestalista predominante. Certamente, nas provincias atlánticas a forestación dos montes veciñais é masiva e enfronta con potenciais aproveitamentos tradicionais que poden avanzar na ligazón monte-agro.

Por outra banda, cómpre ter en conta o complexo contexto rural no que se asentan as áreas xeográficas con propiedades comunitarias. Nelas predominan as tendencias que avanzan cara un avellentamento poboacional, a perda paulatina de emprego agrario e o abandono dos recursos produtivos e dos núcleos de poboación. Estes factores conducen a un progresivo abandono das terras de cultivo e dos espazos forestais (Corbelle e Crecente, 2008) impulsando por unha banda a disociación entre a agricultura e, por outra, as actividades forestais e a falta de xestión do mato (Baptista, 2010). Estes condicionantes favorecen a xeración de importantes problemáticas ambientais, sendo a principal a lacra dos lumes forestais (Fuentes-Santos et al., 2013; Santos-Pereira et al., 2006). Uns incen- 
dios forestais que deixaron de ser rurais para converterse en civís, afectando ás vivendas e provocando vítimas mortais no ano 2017 en Galicia e en Portugal.

Outro aspecto de interese vinculado cos MVMC e cos Baldios consiste no feito de que nos últimos anos estanse a producir cambios normativos diferenciados nos dous espazos xeográficos e que son percibidos de maneira moi diferente polas entidades comunitarias. Así, no caso galego, as recentes modificacións están a xeran preocupación e mesmo mobilización social por parte das entidades comunitarias. Certamente, o mantemento das características intrínsecas á figuras comunitarias e a posibilidade da perda da propiedade, tal e como se entende a dia de hoxe, é unha ameaza latente nas últimas décadas. A modificación da Lei de MVMC realizada a finais do ano 2017 na que se introduce a posibilidade de inserir un Monte Veciñal en grave estado de abandono dentro do Banco de Terras de Galicia cun período de aproveitamento de ate 50 anos acendeu moitas alarmas nas entidades veciñais de Galicia. No mesmo senso, recentes liñas de axudas cunha visión paternalista dos montes veciñais por parte da administración pública, nas que as entidades comunitarias aparecen como parte fundamental dos procesos xa teñen que realizar cesións do terreo veciñal, pero onde as beneficiarias reais son os concellos ${ }^{13}$. Pola contra, no caso de Portugal as recentes modificacións establecidas pola Lei de 2017 son percibidas positivamente polos baldios e as entidades asociativas (Gralheiro, 2018; ) ao establecer unha concepción de baldio máis acaída á realidade actual (Bica et al., 2018) e, consecuentemente, unha nova caracterización de comparte.

Unha das principais problemáticas coas que se encontran as propiedades comunitarias, sobre todo en áreas do interior despoboado, consiste na escaseza de efectivos humanos que conforman as institucións de manexo comunitario, o que certamente dificulta a explotación dos seus recursos propios (Cabana Iglesia, et al., 2011). Sobre esta cuestión, como temos indicado anteriormente, unha definición máis ampla da figura do comuneiro, ao estilo do que acontece cos compartes de Portugal podería axudar a paliar esta casuística en áreas rurais de Galicia, pero, sen lugar a dúbidas, son precisas outras medidas que permitan revitalizar as áreas comunitarias en espazos xeográficos con escaseza de poboación local. O establecemento de ferramentas que posibiliten oportunidades de aproveitamento de parte dos espazos comunitarios para a xente moza con interese en establecerse e emprender proxectos produtivos en áreas rurais pode ser unha actividade a explorar, sempre que os procesos sexan controlados totalmente pola poboación local e que se delimiten as posibles iniciativas produtivas a ámbitos sustentables.

Mais o contexto é certamente moi complexo. Os dados da Dirección Xeral de Ordenación Forestal na $1^{a}$ Revisión do Plan Forestal de Galicia (Consellería do Medio Rural, 2017) amosan a existencia de numerosas eivas administrativas nos MVMC. Así, en 2015, o $10 \%$ das CMVMC de Galicia non dispuña de estatutos vixentes e o 34\% das CMVMC

13 Como as axudas para a creación de parques forestais que ten realizado nos últimos anos a Deputación de Pontevedra. 
non tiñan unha Xunta Reitora actualizada. No tocante ao censo de veciños comuneiros, o $10 \%$ das CMVMC de Galicia non dispuña deste censo e o $50 \%$ si que o tiña pero non estaba actualizado. É dicir, en numerosos casos as Comunidades non teñen estas obrigas administrativas actualizadas. No caso portugués o contexto tamén é dificultoso e moi diverso. Así, na actualidade están constatados tres réximes de xestión diferentes dos Baldios: A coxestión co Estado, que é a modalidade máis empregada con 861 unidades; a xestión exclusivamente polos compartes, é dicir, a autoxestión veciñal, con uns 246 Baldios e, finalmente, tamén se realiza en 334 casos a delegación de competencias nas Juntas de Freguesia (Serra e Ferreira, 2017). Esta coxestión entre o Estado, nomeadamente o ICNF, e os Baldios é un mecanismo que podemos considerar similar ao que acontecido nas últimas décadas entre as CMVMC e a Xunta de Galicia a través dos consorcios ou dos convenios. Na actualidade a Xunta conta con convenios para a xestión pública de monte en 315.000 ha (Consellería do Medio Rural, 2017), das que a meirande parte son veciñais. Unha situación que vai mudar bruscamente nos vindeiros anos, xa que a Xunta ten planeado reducir esta cantidade progresivamente. De feito, a Lei de Montes de Galicia establece a necesidade da finalización dos convenios nun curto prazo de tempo ${ }^{14}$.

A situación, por tanto, está avanzando cara mudanzas e incertezas. Con todo, na ecuación da análise das propiedades comunitarias resulta preciso introducir outros elementos e aportes destas ferramentas colectivas de gobernanza do territorio. Así, como temos sinalado, as propiedades comunitarias deixaron de ser complemento das economías individuais pero están a ocupar, pouco a pouco, novos papeis para as comunidades locais, principalmente a xeración e dinamización das economías locais, promovendo a creación de riqueza, emprego e mellores condicións de vida (de Carvalho, 2017). Efectivamente, cómpre tamén ter en conta que as CMVMC e os Baldios desenvolven importantes tarefas de ámbito social nos espazos rurais. Neste senso, unhas das accións desenvolvidas a nivel social por algunhas Comunidades de Montes consiste no financiamento de locais socioculturais comunitarios nos que a veciñanza poden reunirse e organizar actividades socioculturais. Pola súa banda, nos Baldios é común a colaboración, en forma de axuda económica, coas Instituições Particulares de Solidariedade Social (IPSS) das freguesías locais, entidades sociais que realizan importantes tarefas de apoio a persoas de idades avanzadas ou con diferentes problemáticas. Noutras ocasións, as propiedades comunitarias proporcionan aos habitantes das parroquias ou lugares servizos dos que non dispoñen previamente. Por exemplo, as traídas de augas veciñais en zonas rurais, o mantemento de accesos aos núcleos de poboación, as zonas de lecer como os parques forestais. Mais tamén as entidades veciñais son claves, sobre todo en áreas rurais para o financiamento

14 Os prazos temporais de cancelación ou finalización dos convenios xa foron ampliados con posterioridade ate o 31 de decembro de 2021, existindo controversia en relación cos saldos existentes da xestión pública nalgúns dos montes veciñais e aos procesos de liquidación da débeda como o que establece que se considerará liquidado o saldo debedor dos convenios ou consorcios que sexan obxecto de finalización ou de cancelación cando os seus titulares constitúan unha sociedade de fomento forestal ou pasen a formar parte dela (Presidencia da Xunta de Galicia, 2017). 
de actividades de ámbito cultural ou de lecer, a partir da iniciativa propia ou do apoio ás asociacións culturais, sociais ou veciñais, ás entidades deportivas locais, etc. E mesmo existen casos singulares nos que as propiedades comunitarias son parte fundamental de proxectos de reinserción social a partir da agricultura ecolóxica (Copena e Simón, 2016).

As propiedades comunitarias son entidades xeradoras de emprego e de actividade económica no mundo rural. Nese senso, resulta relevante o papel de axente dinamizador que desenvolven algunhas Comunidades de Montes, cuestión que se pode visualizar en comunidades das catro provincias, pero que se constata sobre todo en comunidades dinámicas vinculadas con áreas poboadas da provincia de Pontevedra en Galicia e con baldios da área do norte. Deste xeito, mediante a xestión dos seus recursos propios, hai entidades comunitarias que xeran emprego e que dinamizan os espazos locais nos que interactúan. Neste senso, cómpre salientar como algunhas das institucións veciñais están comezando a mudar as racionalidades produtivas cara ámbitos non convencionais, articulándose ao redor das premisas vinculadas co concepto de multifuncionalidade (van der Poeg et al., 2009), cuestión que aparece tamén especificamente recollida para o monte (Borras et al., 2017; Carvalho-Ribeiro et al., 2010). Neste paradigma na xestión do monte resulta necesaria a coexistencia das funciones social, económica e ambiental. Esta visión multifuncional, na cal ámbitos como o da agroecoloxía atopa un posible acomodo, enfrontase coas visións maioritarias e convencionais ligadas ao produtivísimo de curto prazo ligado aos monocultivos de crecemento rápido, principalmente de eucalipto, destinados fundamentalmente a la produción de pasta de papel e, máis recentemente, á bioenerxía (Copena e Simón, 2014). Deste xeito, están agromando a ambos lados do Miño iniciativas comunitarias multifuncionais, aínda moi minoritarias, que se desenvolven en diversos ámbitos que impactan sobre a sustentabilidade local e que amosan como é posible apostar por outros modelos de xestión colectiva. Por exemplo, os Baldíos, sobre todo en áreas protexidas, comezan a asumir un papel relevante na conservación do patrimonio cultural (Luz, 2017). Así, se constata a aparición de Baldios que teñen en conta na súa xestión os diferentes recursos patrimoniais (de Carvalho, 2017). E agroman iniciativas que en base ao patrimonio (material e inmaterial) desenvolven estratexias específicas de dinamización local (Copena et al., 2016a). No mesmo senso, aparecen novos aproveitamentos que procuran fortalecer á Comunidade local e a identificación co recurso común. Iniciativas como as que vinculan os Baldios cos recursos micolóxicos van nesa dirección (Serra et al., 2017) ou as que organizan a recolección deste recurso para a obtención de rendas para os membros da comunidade local (Copena et al., 2016b). Tamén se identifican iniciativas veciñais vinculadas cos modos de produción ecolóxicos certificados, tal e como as que se teñen impulsado desde varias entidades comunitarias de Galicia nos ámbitos gandeiros, con propiedade comunitaria de especies de vacún autóctonas en perigo de extinción, no caso dos aproveitamentos micolóxicos e na produción de pequenos froitos (CRAEGA, 2018). Os exemplos de baldios autoxestionados con éxito, como o de Vilarinho (Serra et al., 2016) ou o de Cortes do Meio, están sendo divulgados nos encontros de baldios portugueses abrindo portas a adopción dun posible efecto espello positivo. No mesmo senso, 
as vinculacións entre sociedade civil e propiedade comunitaria aparece nos dous espazos xeográficos, como ocorre para a recuperación de terreos degradados e substitución de especies pirófitas nos Baldios de Ameixeira ou no caso de MVMC como o de Froxán (Cidrás et al., 2018).

Con esta clase de iniciativas as comunidades locais empodéranse, incrementando a súa resiliencia e a capacidade para responder a posibles presións ou perturbacións, tanto internas como externas, aumentando a súa autonomía para determinar estratexias propias de desenvolvemento económico e social. Ademais, fortalécese a identificación da comunidade local cos seus recursos endóxenos e o propio concepto de xestión horizontal dos recursos, dado o modelo asembleario de toma de decisións baixo o que se implementan. Finalmente, exercen un impacto socioeconómico directo nas comunidades locais a partir da xeración de emprego e da dinamización económica a partir dos recursos propios. Isto acontece nun contexto normativo que non favorece o aproveitamento sustentable de recursos endóxenos, posto que as principais liñas de axuda pública non afrontan a aposta por un cambio de modelo produtivo por parte das comunidades. Cómpre lembrar que, a pesares de encontrarnos nun contexto de grandes incertezas en asuntos de grande importancia, como o relativo aos incendios forestais e ao abandono dos recursos do mundo rural, as políticas públicas non están a afrontar o cerne dos problemas mantendo fundamentalmente as dinámicas das últimas décadas. O caso específico da enerxía eólica nos montes veciñais, onde non existe posibilidade da autoxestión do aproveitamento do recurso vento para a produción de electricidade a partir da posta en marcha de parques eólicos de propiedade da poboación local resulta clarificador. Esta actividade, que se ten desenvolvido fortemente nas áreas rurais de Galiza e Portugal desde mediados dos anos noventa, xerando facturacións de centos de millóns de euros anuais faise sen que os propietarios dos terreos onde se localiza o recurso poidan desenvolver iniciativas colectivas para aproveitar un recurso endóxeno e renovable, ficando con escasas contías do negocio obtido polas empresas promotoras.

Os exemplos de dinamización social e económica existente nas CMVMC e nos Baldios que están aparecendo dan conta de como estas ferramentas democráticas de xestión do territorio teñen capacidade para poder favorecer o desenvolvemento rural (Bassi e Carestiato, 2016) e a mellora da calidade de vida das persoas habitantes nas contornas onde existe a propiedade comunitaria. Non obstante, cómpre un acompañamento normativo que favoreza a posta en marcha de novas iniciativas. No mesmo senso, desde os ámbitos de asesoramento, resulta necesario introducir aspectos vinculados coa multifuncionalidade e fortalecer a resiliencia das comunidades locais nun contexto de incerteza onde moitos aspectos relevantes están en xogo (os incendios forestais, o futuro do mundo rural, etc). Nese senso, a aposta por novos modelos onde a cuestión agraria e o monte volvan interaccionar e onde se favoreza a autoxestión das comunidades en base a criterios de sustentabilidade pode ser de grande importancia. Neste contexto, dados os exemplos singulares identificados neste traballo (moitos deles recentes con escasa traxectoria temporal), considérase necesaria a realización de novas investigacións e análises directamen- 
te cos axentes comunitarios que nos permitan identificar con maior consistencia os novos procesos, aproveitamentos e roles que están aparecendo nos baldios e nos MVMC.

\section{CONCLUSIÓNS}

No territorio galego e no norte e centro de Portugal a propiedade comunitaria do monte mantén unha gran relevancia territorial e importancia socioeconómica nas áreas rurais. Estas propiedades singulares, que se encadran dentro do contexto do debate científico sobre o manexo dos recursos de uso común, contan cunhas características diferentes das propiedades públicas e privadas. Estas características, que son alleas á racionalidade do sistema económico imperante, posibilitan a utilización de lóxicas colectivas vinculadas coa procura do beneficio común e a sustentabilidade no aproveitamento dos recursos.

Como temos visto no artigo, os MVMC e os Baldios, que foron parte fundamental do sistema agrario tradicional nos dous territorios, foron perdendo as súas funcións para as economías locais de subsistencia. Así, pasaron a converterse en espazos forestados por especies de crecemento rápido a pesares da resistencia das poboacións locais. Cando se recuperaron as propiedades comunitarias, as comunidades locais perderan as ligazóns con estas áreas e o custe de oportunidade derivado dos aproveitamentos existentes dificultou unha nova reconstitución real do complexo agro-monte. Nas últimas décadas, con vaivéns e dificultades que xorden desde o ámbito normativo, as entidades de acción colectiva teñen sufrido o dificultoso contexto no que se atopa o mundo rural. Un contexto de abandono e no que os incendios forestais son o grande problema socioambiental de Galicia e do norte e centro de Portugal.

Pola contra, nesta situación de grandes incertezas, de dificultades e no que se pon en xogo cuestións tan importantes como o futuro do rural e a loita contra os incendios forestais, están agromando procesos e experiencias de interese impulsadas polas entidades comunitarias. Deste xeito, na investigación realizada se constata a posta en marcha, a partir da acción colectiva e dentro do paradigma da multifuncionalidade, de novas iniciativas de interese baixo lóxicas sustentables. Nelas, as entidades comunitarias exercen novos papeis vinculados coa dinamización económica e social a nivel local utilizando os recursos endóxenos cos que contan e abrindo novas oportunidades para o fortalecemento e o mantemento das entidades de manexo colectivo das propiedades comunitarias.

As vindeiras décadas serán decisivas para verificar cales serán as funcións e as apostas sociais, económicas e ambientais desempeñadas polas CMVMC e os Baldios. Certamente, no contexto de incerteza no que nos atopamos, os novos ámbitos de actuación que vaian construíndo (ou recuperando) as entidades veciñais e que permitan avanzar na multifuncionalidade das propiedades comunitarias e na xeración de actividade económica a nivel local, serán elementos clave para poder avanzar nun futuro máis sustentable para os espazos rurais de Galicia e Portugal. 


\section{BIBLIOGRAFÍA}

Alló, M.; Loureiro, M.L. (2016): «Evaluating the fulfillment of the principles of collective action in practice: A case study from Galicia (NW Spain)», Forest Policy and Economics, 73, pp. 1-9.

Agrawal, A. (2014): «Studying the commons, governing common-pool resource outcomes: Some concluding thoughts». Environmental Science \& Policy, 36, pp. 86-91

Araral, E. (2014): «Ostrom, Hardin and the commons: A critical appreciation and a revisionist view». Environmental Science \& Policy, 36, pp. 11-23.

Balboa, X. (1990): «O Monte en Galicia». Vigo: Edicións Xerais.

Balboa, X.; Besteiro, B.; Fernández, X.; Fernández, L.; Jordán, M.; López, E.; Soto, D.; Viso, P. (2006): «Os montes veciñais en man común: o patrimonio silente». Natureza, economía, identidade e democracia na Galicia rural. Vigo: Edicións Xerais.

Baptista, F.O. (2010): «Baldios. A erosão da propriedade comunitária», en: Baptista, F.O. (Ed.), O Espaço Rural. Declínio da Agricultura. Lisboa: Celta.

Bassi, I.; Carestiato, N. (2016): «Common property organisations as actors in rural development: a case study of a mountain area in Italy». International Journal of the Commons, 10(1), pp. 363-386.

Bica, A., Carvalho, A. Gralheiro J.C. (2018): Breve enquadramento histórico e jurídico em áreas comunitárias. BALADI-Federação Nacional de Baldios: Vila Real.

Borrass, L.; Kleinschmit, D.; Winkel, G. (2017): «The "German model" of integrative multifunctional forest management-Analysing the emergence and political evolution of a forest management concept». Forest Policy and Economics, 77, pp. 16-23.

Bouhier, A. (2001): «Galicia: ensaio xeográfico de análise e interpretación dun vello complexo agrario». Santiago de Compostela: Consellería de Agricultura, Gandería e Política Agroalimentaria. Xunta de Galicia (Tradución da versión orixinal en francés de 1979).

Brouwer, R. (1995): «Baldios and common property resource management in Portugal». Unasylva, 180, 37-43

Caballero, G. (2014): «Community-based forest management institutions in the Galician communal forests: A new institutional approach». Forest Policy and Economics, 50, pp. 347-356.

Carvalho-Ribeiro, S.M.; Lovett, A.; O’Riordan, T. (2010): «Multifunctional forest management in Northern Portugal: Moving from scenarios to governance for sustainable development». Land Use Policy, 27, pp. 1111-1122.

Cassell, C.; Symon, G. (2004.): «Essential Guide to Qualitative Methods in Organizational Research», London: Sage Publications, pp. 154-164.

Cidrás, D; Lois-González, R.C.; Valerià, P. (2018): «Rural Governance against Eucalyptus Expansion in Galicia (NW Iberian Peninsula)». Sustainability, 10, 3396.

Consellería do Medio Rural. (2014): «Explotación do Rexistro de Montes Veciñais en Man Común». http://mediorural.xunta.gal 
Consellería do Medio Rural. (2018): «Plan de prevención e defensa contra os incendios forestais de Galicia (PLADIGA)». http://mediorural.xunta.gal/areas/forestal/incendios_forestais/pladiga_2018/

Consellería do Medio Rural. (2017): «1 $1^{\text {a }}$ Revisión do Plan Forestal de Galicia».

Consello de Agricultura Ecolóxica de Galicia-CRAEGA. (2018): «Operadores certificados».

Copena Rodríguez, D.; Copena Rodríguez, D. Simón Fernández, X. (2016a): «A posta en valor do patrimonio apícola cereiro tradicional: análisis da experiencia comunitaria da CMVMC de Paraños». La Descomunal. Revista Iberoamericana de Patrimonio y Comunidad, 2, pp. 237-248.

Copena Rodríguez, D.; Simón Fernández, X. (2014): «La producción de energía eléctrica a partir de la biomasa forestal primaria: análisis del caso gallego». Revista Galega de Economía, 23 (2), pp. 91-112.

Copena Rodríguez, D.; Simón Fernández, X. (2016b): «Ação coletiva e horticultura social nos montes comunais da Galiza: O Programa Verdear». Livro de Resumos do I Colóquio Nacional de Horticultura Social e Terapêutica. Estoril, Portugal.

Copena Rodríguez, D.; Simón Fernández, X.; Pérez Neira, D. (2016): «O aproveitamento do recurso micolóxico como oportunidade de desenvolvemento rural nos montes veciñais de Galicia». En Construíndo Coñecemento Agroecolóxico. Cambiando os Modelos de Consumo para Construír Sistemas Agroalimentarios Sustentables; Simón Fernández, X., Copena Rodríguez, D., Pérez Neira, D., Eds.; Grupo de Investigación en Economía Ecolóxica, Agroecoloxía e Historia: Vigo, pp. 204-215.

Corbelle Rico, E.; Crecente Maseda, R. (2008): «O abandono de terras: concepto teórico e consecuencias». Revista Galega de Economía, 17(2), pp. 47-62.

De Carvalho, A. (2017): «Baldio: do Regime Florestal e Co-Gestão à Economia Local e Solidária». BALADI-Federação Nacional de Baldios, Vila Real.

Estêvão, J.A. (1983): «A florestação dos baldios». Análise Social, XIX(77-78-79), $3^{\circ}, 4^{\circ}, 5^{\circ}$, pp. $1157-1260$.

Fuentes-Santos, I.; Marey-Pérez, M.F.; González-Manteiga, W. (2013): «Forest fire spatial pattern analysis in Galicia (NW Spain) ». Journal of Environmental Management, 128(15), pp. 30-42.

Gautam, A.P.; Shivakoti, G.P. (2005): «Conditions for Successful Local Collective Action in Forestry: Some Evidence From the Hills of Nepal». Society \& Natural Resources, 18(2), pp. 153-171.

Gómez-Vázquez, I.; Álvarez-Álvarez, P.; Marey-Pérez, M.F. (2009): «Conflicts as enhancers or barriers to the management of privately owned common land: A method to analyze the role of conflicts on a regional basis». Forest Policy and Economics, 11, pp. 617-627.

Gralheiro JC. (2018): «Dos baldios, até à Lei 75/2017, de 17 de agosto». Edições Esgotadas. 
Graziano-Ceddia, M., Gunter, U., Corriveau-Bourquec, A. (2015): «Land tenure and agricultural expansion in Latin America: The role of Indigenous Peoples' and local communities' forest rights». Global Environmental Change, 35, pp. 316-322.

Hardin, G. (1968): «The tragedy of the commons». Science, 162, pp. 1243-1248.

Instituto da Conservação da Natureza e das Florestas-ICNF. (2013): «IFN6 - Áreas dos usos do solo e das espécies florestais de Portugal continental. Resultados preliminares». Lisboa: Instituto da Conservação da Natureza e das Florestas.

Instituto Galego de Estatística-IGE. (2016): «Distribución xeral de terras». https://www. ige.eu

Lopes, L.F.G.; Bento, J.M.R.S.; Cristovão, A.F.A.C.; Baptista, F.O. (2013): «Institutionalization of common land property in Portugal: Tragictrends between "Commons" and "Anticommons"». Land Use Policy, 35, pp. 85- 94.

Luz, A.L. (2017): «Entre subsídios e turismo: instituições e poder na gestão dos baldios do parque nacional da Peneda-Gerês». Finisterra, LII(105), pp. 7-27.

Marey-Pérez, M.F.; Gómez-Vázquez, I.; Díaz-Varela, E. (2010): «Different approaches to the social vision of communal land management: the case of Galicia (Spain)». Spanish Journal of Agricultural Research, 8(3), pp. 848-863.

Ministerio de Agricultura, Alimentación y Medio Ambiente, España. (2008): «Tercer Inventario Forestal Nacional».

Ministerio de Agricultura, Pesca y Alimentación, (2016): «Estadística Anual de Cortas de Madera».

Ostrom, E. (1990): «Governing the Commons: The Evolution of Institutions for Collective Action». Cambridge University Press, New York.

Rico Boquete, E. (2000): «Política forestal y conflictividad social en el noroeste de España durante el primer franquismo, 1939-1959». Historia Social, 38, pp. 117-140.

Santos Castroviejo, I. (2003). «A investigación-acción-participativa como metodoloxía científica». Cooperativismo e Economía Social, 25, pp. 7-20.

Santos-Pereira, J.; Rêgo, F.; Silva, J.; Silva, T.; Pereira, J.M.; Carreiras, J.; Silva, J.; Vasconcelos, M. (2006): «Incêndios Florestais em Portugal». Lisboa: ISA.

Serra, R.; Ferreira, P. (2017): «Governação comunitária de florestas para crianças». Coimbra: Centro de Estudos Sociais.

Serra, R.; Rodrigues, E.; García-Barrios, R. (2017): «Mushrooming Communities: A Field Guide to Mycology in the Community Forests of Portugal». Sustainability, 9, 924.

Serra R., Ferreira, P., Skulska, I., Alavez-Vargas, M., Salgado, A., Nunes J.A., GarciaBarrios, R. (2016): «Education for Sustainability in the Context of Community Forestry». En: Castro P., Azeiteiro U., Bacelar-Nicolau P., Leal Filho W., Azul A. (eds) Biodiversity and Education for Sustainable Development. World Sustainability Series. Springer.

Simón Fernández, X.; Cerdeira Pérez, J.; Collazo Villar, A.J.; Domínguez García, M.D. (1999): «Guia para fazer umha investigaçom participativa». Lugo: Editorial Fouce. 
Slaev, A.D.; Collier, M. (2018): «Managing natural resources: Coasean bargaining versus Ostromian rules of common governance». Environmental Science and Policy, 85, pp. 47-53.

Soto Fernández, D.; Fernández Prieto, L. (2004): «Política forestal e conflictividade nas terras comunais de Galicia durante o franquismo (1939-1975) » En Freire D, Fonseca I, Godinho P (editores): Mundo Rural, Transformaçao e resistencia na Península Ibérica (século XX). Lisboa: Colibri, Editors:, pp.225-249.

van der Ploeg, J.D.; Laurent, C.; Blondeau, F.; Bonnafous, P. (2009): «Farm diversity, classification schemes and multifunctionality». Journal of Environmental Management, 90, S124-S131. 